\title{
Estimating Relative Risk Aversion, the Discount Rate, and the Intertemporal Elasticity of Substitution in Consump- tion for Brazil Using Three Types of Utility Function*
}

\author{
João Victor Issler** \\ Natalia Scotto Piqueira**
}

\begin{abstract}
Using the generalized method of moments, we estimate structural parameters related to relative-risk aversion, the discount rate of future utility, and the intertemporal elasticity of substitution in consumption for the Brazilian economy. Estimates are provided for three types of utility function based on the consumption capital asset pricing model: constant relative risk aversion utility, utility with external habit, and Kreps-Porteus utility. These results are analyzed and then compared to previous results using Brazilian and U.S. data. Moreover, we perform over-identifying restrictions tests of all estimated models to investigate the possible existence of the equity premium puzzle in Brazil.

The overall results show that Brazilian consumers have a relatively high discount rate, a low intertemporal elasticity of substitution, and a high relative risk aversion coefficient. Also, there is no evidence of the existence of the equity premium puzzle in Brazil.
\end{abstract}

* This article is a revised version of Natalia S. Piqueira's Masters Thesis, done under the supervision of João Victor Issler. We thank Marco Antonio Bonomo, René Garcia, Ajax Moreira, an anonymous referee and Carlos Martins Filho (Editor) for their suggestions on an earlier version of this article. All the remaining errors are ours. We also thank CNPq and PRONEX for their financial support.

** Graduate School of Economics, Getulio Vargas Foundation, Praia de Botafogo, 190, s.1100, Rio de Janeiro, RJ., 22253-900, jissler@fgv.br

Brazilian Review of Econometrics Rio de Janeiro v.20, $\mathrm{n}^{\circ} 2$, pp.201-239 Nov.2000 


\section{Resumo}

Nesse trabalho estima-se, usando o método generalizado dos momentos e dados brasileiros, os parâmetros estruturais do modelo CCAPM (consumption capital asset pricing model) a partir de três classes de funções utilidade distintas: função utilidade potência (CRRA), utilidade com hábito externo, e aversão ao desapontamento (Kreps-Porteus). Estes parâmetros estruturais estão associados à aversão ao risco, à elasticidade de substituição intertemporal no consumo e à taxa de desconto intertemporal da utilidade futura. Os resultados aqui obtidos são analisados e comparados com resultados anteriores para dados brasileiros e americanos.

Adicionalmente, testa-se econometricamente todos os modelos estruturais estimados a partir do teste de restrições de sobre-identificação, para investigar, da forma mais abrangente possível, se há ou não equity premium puzzle para o Brasil. Os resultados surpreendem, dado que, em raríssimas ocasiões, se rejeita as restriçōes implícitas nesses modelos. Logo, conclui-se que não há equity premium puzzle para o Brasil.

Key Words: CCAPM, GMM, Risk aversion, discount rate, Intertemporal elasticity of substitution in consumption.

JEL Code: C3, E2, G1.

\section{Introduction.}

The purpose of this paper is to analyze the behavior of Brazilian consumers regarding risk and inter-temporal substitution in consumption. We investigate these issues through GMM estimates based on the CCAPM (consumption capital asset pricing model). The basic idea of the CCAPM (e.g., Lucas, 1978) is that, in order to implement their future consumption plans, agents store wealth in the form of assets. Hence, the properties of the asset return series must be related to the properties of the consumption series and the agent's degree of risk aversion, discount factor, and intertemporal elasticity of substitution in consumption. 
For U.S. data, the basic CCAPM with time-additive CRRA (constant relative risk aversion) utility function did not perform well visa-vis the data, resulting in an important macroeconomic puzzle - the equity premium puzzle, originally presented by Mehra and Prescott (1985). For data from 1889 to 1978 the average equity premium vis-avis government bonds was $6.18 \%$ per year. Simulating the model for parameter values considered reasonable (a relative risk aversion coefficient between zero and ten), Mehra and Prescott concluded that the observed equity premium was inconsistent with the model, unless a risk aversion coefficient between 30 and 40 was considered.

Formal econometric tests for the CCAPM were conducted by Hansen and Singleton $(1982,1984)$ with CRRA utility and by Epstein and Zin (1991) with Kreps-Porteus utility, inter-alia. These tests exploited the over-identifying restrictions of the respective models (Hansen (1982)), and can be interpreted as formal econometric tests for the equity premium puzzle. This happens because the tests evaluate simultaneously the implied restrictions of the Euler Equations on government bonds (risk-free assets) and on stock returns (risky asset). For the U.S. economy, these restrictions were consistently rejected either by Hansen and Singleton or by Epstein and Zin, confirming the puzzle indicated by Mehra and Prescott.

As a response to the equity-premium puzzle, the basic CCAPM with time-additive CRRA utility was re-formulated in two directions. The first tried to explain the puzzle from the existence of market imperfections - incomplete markets (Mankiw, 1986), liquidity constraints (Scheinkman and Weiss, 1986) and transaction costs (Grossman and Laroque, 1989) - which implied the non-validity of a representative consumer model due to the agent's restricted access to the asset markets. In this case, the model was re-formulated to incorporate heterogeneous agents. The second focused on incorporating a more general class of preferences for the representative consumer, 
allowing for non-separability over time, for alternative ways of formulating preferences over risk, and by the use of non-expected utility models.

For Brazilian data, estimates of the relative risk aversion coefficient for the basic linearized model (under log-normality) have already been performed by Reis et alli (1998). Their results, in some cases, showed significant estimates of risk aversion between 3 and 5 . However, for the log-linearized model to be valid, returns on assets and consumption must obey a series of strong parametric restrictions. Also, Reis et alli only consider the accumulation of assets in the form of government bonds, which does limit the scope of the empirical results.

In this paper, the issue of risk aversion and inter-temporal substitution for Brazilian consumption is studied in a broader way. Following the second strand of the international literature described above, structural parameters of the Brazilian economy are estimated using the consumption smoothing model with three different utilityfunction parameterizations. These are the time-additive CRRA utility (e.g. Hansen and Singleton $(1982,1983))$, the external habit utility (e.g. Abel (1990)), and Kreps-Porteus utility (e.g. Epstein and Zin $(1989,1991))$. Moreover, in the empirical implementation, the representative consumer can allocate its wealth in two different assets: government bonds and a stock portfolio.

The econometric technique used in estimation is the generalized method of moments (GMM), which, besides allowing the estimation of structural parameters in the models, also allows testing the restrictions implied by the Euler Equations for each model, resulting in an equity premium puzzle test for Brazil. Data for two different time frequencies (annual and quarterly) and a large range of instrument sets are used. The great variety of possible data frequencies, utility functions, and instrument sets, allows verifying the robustness 
of the empirical results for Brazil. This constitutes an original and necessary effort to bridge the gap between the Brazilian and International literature. Even regarding the latter, we are unaware of any empirical effort similar to ours contained in a single article.

In section 2 the three macroeconomic theoretical models to be tested are described. In section 3 we present a description of the data and the estimation method. The empirical results are presented in section 4 and the conclusions in section 5 .

\section{Theoretical Models.}

Consider a single-good general equilibrium model with infinite horizon and identical agents. The representative agent's general problem is:

$$
\max _{\left[\left\{C_{t+j}\right\}_{j=0}^{\infty},\left\{\theta_{t+j+1}\right\}_{j=0}^{\infty}\right]} U_{t}(\cdot)
$$

subject to the sequence of constraints (2) below:

$$
C_{t+j}+q_{t+j} \theta_{t+j+1} \leq\left[q_{t+j}+q_{t+j}^{*}\right] \theta_{t+j}+y_{t+j}, \forall j=0,1,2 \ldots
$$

There are $\mathrm{N}$ assets in the economy, where $\theta_{t+j(N \times 1)}, q_{t+j(N \times 1)}$ is a vector with their respective quantities and prices and $q_{t+j(N \times 1)}^{*}$ are vectors with their respective dividends. In each period, the agent receives an exogenous income $y_{t+j}$, which is a state variable in the consumer problem.

\subsection{The CRRA Time-Additive Utility Function.}

Following Hansen and Singleton (1982), the inter-temporal utility function in the benchmark model is a von Neumann-Morgenstern utility function (time-additive): 
Risk Aversion, Discount Rate

$$
U_{t}=E_{t}\left[\sum_{j=0}^{\infty} \beta^{j} u\left[C_{t+j}\right]\right]
$$

where $C_{t}$ is real aggregate consumption per capita, $E_{t}($.$) is the condi-$ tional expectation on the information available to the agent at period $t$ and $\beta$ is the intertemporal discount rate, $0<\beta<1$. The maximization of (3) subject to sequence (2) results in the following $N$ first-order conditions (Euler Equations):

$$
u^{\prime}\left[C_{t}\right]=E_{t}\left\{\beta u^{\prime}\left[C_{t+1}\right]\left(1+R_{i, t+1}\right)\right\}, \forall i=1, \ldots ., N,
$$

where the real rate of return for asset $i$ at period $t+1$ is defined as $R_{i, t+1}:=\frac{q_{i, t+1}+q_{i, t+1}^{*}}{q_{i, t}}-1$, where $q_{i, t+1}$ and $q_{i, t+1}^{*}$ are respectively the price and return of asset $i, i=1,2, \ldots N$, in period $t+1$, with a similar notation applying to $q_{i, t}$.

Dividing both sides of (4) by $u^{\prime}\left[C_{t}\right]$ we have:

$$
1=E_{t}\left[\left(1+R_{i, t+1}\right) M_{t+1}\right], \forall i=1, \ldots, N
$$

where $M_{t+1}$ is pricing kernel (or stochastic discount factor).

In this first model, the instantaneous utility function is parameterized as CRRA:

$$
u\left(C_{t}\right)=\frac{C_{t}^{1-\gamma}-1}{1-\gamma}
$$

where $\gamma$ is the relative risk aversion coefficient. The main objection to this utility function specification is that only one parameter $(\gamma)$ governs both the relative risk aversion coefficient and the inter-temporal elasticity of substitution in consumption $\psi$, since: 


$$
\begin{aligned}
\psi & \equiv \frac{\partial \ln \left(\frac{C_{t+1}}{C_{t}}\right)}{\partial \ln R_{t+1}} \\
& =\frac{1}{\gamma}
\end{aligned}
$$

For example, a risk averse agent ( $\gamma$ high) will not alter his consumption pattern significantly in response to interest rate variations $(\psi$ low), given that risk aversion is the reciprocal of the inter-temporal elasticity of substitution.

Applying the utility function parameterization to (4), we obtain:

$$
1=E_{t}\left[\beta\left(\frac{C_{t+1}}{C_{t}}\right)^{-\gamma}\left(1+R_{i, t+1}\right)\right], \forall i=1, \ldots ., N
$$

and, in this case, the pricing kernel is a function of consumption growth:

$$
M_{t+1}^{C R R A}=\beta\left(\frac{C_{t+1}}{C_{t}}\right)^{-\gamma}
$$

2.2 External Habit Model ("Catching up with the Joneses").

The way that habit formation is introduced in this general equilibrium setting is based on the assumption of a positive effect from past consumption - viewed as consumer's "habit" - on the agent's instantaneous utility function, allowing for non-separability of the utility function over time. The intertemporal utility function will also depend on $v$, a time-preference parameter: 


$$
U_{t}=E_{t} \sum_{j=0}^{\infty} \beta^{j} u\left[C_{t+j}, v_{t+j}\right]
$$

Differences in the functional form of $u($.$) and v($.$) result in dif-$ ferent habit formation models. For alternative specifications see, for example, Abel (1990) or Constantinides (1990). Following Abel, we specify the function $v($.$) here as follows:$

$$
v_{t}:=\left[C_{t-1}^{D} \bar{C}_{t-1}^{1-D}\right]^{\kappa}
$$

where $C_{t-1}$ is the agent's own consumption at $t-1, \bar{C}_{t-1}$ is aggregate consumption at $t-1$ and $\kappa$ is the parameter controlling the time separability of the utility function. In order to have external habit, we set $D=0$ and $\kappa>0$ (therefore, the agent's habit level is a state variable), whereas in the internal habit model $D=1$ and $\kappa>0$ (therefore, the agent's choice of consumption level today affects the habit level for the next period). In Abel's (1990) external habit model, also known as "Catching up with the Joneses"1, the instantaneous utility function is parametrized as:

$$
u\left(C_{t}, v_{t}\right)=\frac{\left[\frac{C_{t}}{v_{t}}\right]^{1-\gamma}}{1-\gamma}
$$

Using the external habit hypothesis ( $D=0$ and $k>0$ ), plugging (12) into (13), and substituting the result in (11), the representative agent's problem becomes:

\footnotetext{
${ }^{1}$ In the external habit model, the agent's relevant habit level is the one observed in his "neighborhood" (Joneses) on the previous period, resulting on the term "Catching up with the Joneses".
} 


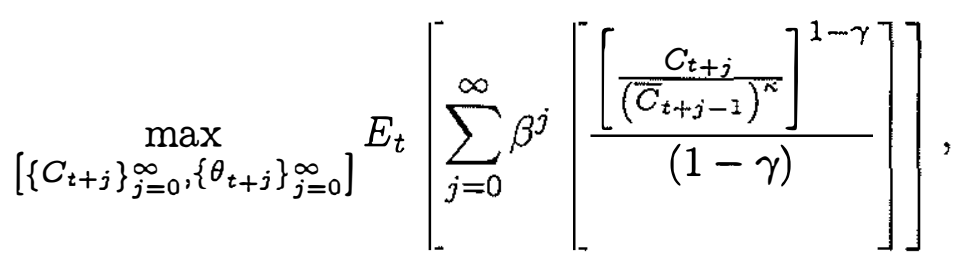

subject to sequence (2), where $C_{t+j}$ represents individual consumption and $\bar{C}_{t+j-1}$ represents aggregate consumption, which is taken parametrically by the agent in the optimization problem. Solving the representative agent's problem and imposing the equilibrium condition that individual and aggregate consumption are identical, we obtain the following $N$ Euler equations:

$$
1=E_{t}\left[\beta\left(\frac{C_{t}}{C_{t-1}}\right)^{\kappa(\gamma-1)}\left(\frac{C_{t+1}}{C_{t}}\right)^{-\gamma}\left(1+R_{i, t+1}\right)\right], \forall i=1, \ldots, N
$$

so that the pricing kernel in this model includes an extra term related to lagged consumption growth:

$$
M_{t+1}^{E H}=M_{t+1}^{C R R A}\left(\frac{C_{t}}{C_{t-1}}\right)^{\kappa(\gamma-1)}
$$

The parameter $\kappa$ controls the degree of time separability in consumption. Note that, when $\kappa=0$, we are back to time-additive CRRA utility, i.e., equation (9).

Because the representative consumer takes aggregate consumption parametrically, the inter-temporal elasticity of substitution in consumption is $\psi=1 / \gamma$ for the external habit model. Notice that the same is not true for the internal habit model, where computation of $\psi$ is more involved. 


\subsection{Kreps-Porteus utility type model.}

The third model discussed here follows Epstein and Zin (1989, 1991), being a generalization of the expected utility case, as proposed by Kreps and Porteus (1978). This specification allows the separation between risk aversion and inter-temporal substitution in consumption - one of the main criticisms directed towards the CRRA utility model ${ }^{2}$. The basic idea is that the representative agent forms a certainty equivalent for her future utility using her preferences over risk. This certainty equivalent is combined with current consumption in $t$ (deterministic) via an aggregating function $(W()$.$) , in order$ to obtain the intertemporal utility function.

The agent's future utility is defined as $\widetilde{U}_{t+1}$ and $\mu\left[\widetilde{U}_{t+1} \mid I_{t}\right]$ is her certainty equivalent, we arrive at the following inter-temporal utility function specification:

$$
U_{t}=W\left[C_{t}, \mu\left[\widetilde{U}_{t+1} \mid I_{t}\right]\right]
$$

Notice that risk aversion is synthetized in $\mu($.$) while the inter-$ temporal part is in $(W()$.$) . The way the certainty equivalent (the$ preference over risk) is modeled is denoted as $\alpha$-mean, or constant relative risk aversion expected utility:

$$
\begin{aligned}
\mu\left[\widetilde{U}_{t+1} \mid I_{t}\right] & =\left[E_{t}{\widetilde{U^{\alpha}}}_{t+1}\right]^{1 / \alpha}, 0 \neq \alpha<1, \\
\log \left[\mu\left[\widetilde{U}_{t+1} \mid I_{t}\right]\right] & =E_{t} \log \widetilde{U}_{t+1}, \quad \alpha=0 .
\end{aligned}
$$

\footnotetext{
${ }^{2}$ The main criticism on the non-identification of both parameters within the CRRA model, according to Hall (1988), is based on the following argument: the intertemporal elasticity of substitution refers to the investors' propensity for altering their consumption between time periods (which is also defined when there is no uncertainty), whereas the risk aversion coefficient refers to the investors' propensity for altering their consumption between different states of the world (which is also defined in a one-period model).
} 
The aggregating function is parameterized as a constant elasticity of substitution (CES) function:

$$
U_{t}=\left[(1-\beta) C_{t}^{\rho}+\beta\left(E_{t} \widetilde{U}_{t+1}^{\alpha}\right)^{\frac{\rho}{\alpha}}\right]^{\frac{1}{\rho}}, \text { for } 0 \neq \rho<1
$$

where the intertemporal elasticity of substitution in consumption $(\psi)$ is given by

$$
\psi=\frac{1}{(1-\rho)}
$$

The $\alpha$ parameter reflects the agent's behavior towards risk. In the above specification the relative risk aversion coefficient $\gamma$ is constant, $\gamma=1-\alpha$. Note, that when $\alpha=0$, we are back to the expected utility model with logarithmic preference. When $\alpha=\rho$, once again we have an additively separable utility function.

The maximization of (19) subject to sequence (2) results in the following $N$ Euler Equations - Epstein and Zin (1991):

$$
1=E_{t}\left[\beta^{\eta}\left(\frac{C_{t+1}}{C_{t}}\right)^{\eta(\rho-1)} \widetilde{B}_{t+1}^{\eta-1}\left(1+R_{i, t+1}\right)\right], \forall i=1, \ldots, N
$$

where $\eta:=\frac{\alpha}{\rho}$ and $\widetilde{B}_{t+1}$ is the optimum portfolio's gross return ${ }^{3}$.

This specification allows, therefore, the inclusion of a pricing ke rnel term related to the aggregate uncertainty in the economy, captured by $\widetilde{B}_{t+1}$ : the pricing kernel is a geometrical average between the additively separable (CRRA) model - that reflects consumption growth - and the term that reflects aggregate uncertainty:

\footnotetext{
${ }^{3}$ Epstein and Zin represent this variable using the returns in a stock index traded at the New York Stock Exchange as a proxy.
} 


$$
M_{t+1}^{E Z}=\left(M_{t+1}^{C R R A}\right)^{\eta}\left(\frac{1}{\widetilde{B}_{t+1}}\right)^{1-\eta}
$$

In order to test the separability hypothesis, the authors use a system of Euler Equations that includes (21) and the model's nonseparable logarithmic specification as in the case of preference over risk $(\alpha=0 ; \rho \neq 0)$ :

$$
E_{t}\left[\frac{\left[\beta\left(\frac{C_{t+1}}{C_{t}}\right)^{(\rho-1)} \widetilde{B}_{t+1}\right]^{\eta}-1}{\eta}\right]=0 .
$$

\section{Data and Estimation Method.}

\subsection{Database.}

The systems of equations formed by (9), (15), and (21) and (23), were respectively estimated for Brazilian data at different time frequencies. Previous empirical work in the international literature (Hansen and Singleton, 1982, 1983; Epstein and Zin, 1991) used monthly data, arguing that they are more likely to capture the agent's timing decision. Moreover, these models are adequate for aggregate consumption of non-durable goods data ${ }^{4}$. We used consumption and asset return series in two different frequencies: annual, because it is the officially published series for national consumption (although it might not fully capture the agent's timing decision and does not distinguish between durable and non-durable goods), and

\footnotetext{
${ }^{4}$ See Bernanke (1985) for an explanation on the durable-good problem.
} 
quarterly, which was constructed from the annual series, but, does not distinguish durable from non-durable goods.

We also considered using a monthly production series, of domestic non-durable goods for the city of São Paulo as a proxy for monthly non-durable goods consumption. Unfortunately, this series, besides only having regional coverage, also has a structural break for 1990:1, when its level changed $50 \%$ relative to the previous month, which represents an outlier behavior for a consumption proxy ${ }^{5}$.

The annual nominal aggregate consumption data, from 1975 to 1994, were obtained from FIBGE's ${ }^{6}$ national accounts. To obtain real aggregate consumption, this series was deflated by a general price index - IGP-DI. As the model requires real aggregate consumption per capita, real consumption was divided by population, also published by FIBGE. For quarterly frequency, aggregate consumption data is not directly calculated in national accounts, although we do have GDP series and gross fixed investment series for that time frequency. For the 1975:1 to 1994:4 we used the same series as in Reis et alli (1998), where the quarterly gross fixed investment and current account balance series were subtracted from the quarterly nominal GDP series, in order to obtain a quarterly nominal consumption series. The nominal aggregate consumption series was then deflated by IGP-DI and, subsequently, real consumption per capita was obtained by dividing it by the population series ${ }^{7}$. The real per capita con-

\footnotetext{
${ }^{5}$ We thank an anonymous referee for pointing this out. A previous version of this article contains the analysis of that monthly series.

${ }^{6}$ The aggregate consumption series from national accounts, is calculated as a residual, and is subject to measurement error. GMM estimation (and the over-identification test) allows inferring if those errors affect the estimates. For a more detailed description of the problem, see Reis et alli (1998).

${ }^{7}$ As there is no available quarterly data for poupulation, a linear interpolation on the annual
} 
sumption series, was then seasonally adjusted, given that it showed a strong seasonal component, which may be due to the fact that the consumption series was obtained from GDP and gross fixed investment. We should point out that the series used in international studies are also seasonally adjusted, which makes our results directly comparable to them ${ }^{8}$.

The interest rate series - return on government (federal) debt (published by Andima, the National Association of Open Market Institutions) - has as its source the Central Bank and were accumulated to obtain the annual and quarterly series from monthly observations.

The asset return series used for the risky asset was the return rate of BOVESPA. The monthly BOVESPA index for the 1975:1 to $1998: 12$ period was obtained from BOVESPA, and the monthly observations were accumulated to obtain the quarterly series, which was then deflated in the same way as the interest series.

Figures 1 and 2 show the data used here in annual and quarterly frequencies respectively. It is worthwhile noticing the wide variation of returns observed for the BOVESPA index.

\footnotetext{
series was done, once the population series is very smooth.

${ }^{8}$ The equations were also estimated for the quarterly series model without correcting the seasonal adjustability but including seasonal dummies in the Euler Equations and the instruments, in an identical procedure to Reis et alli's(1998), making the results in that case directly comparable.
} 
João Victor Issler and Natalia Scotto Piqueira

Figure 1: Data on Annual Frequency

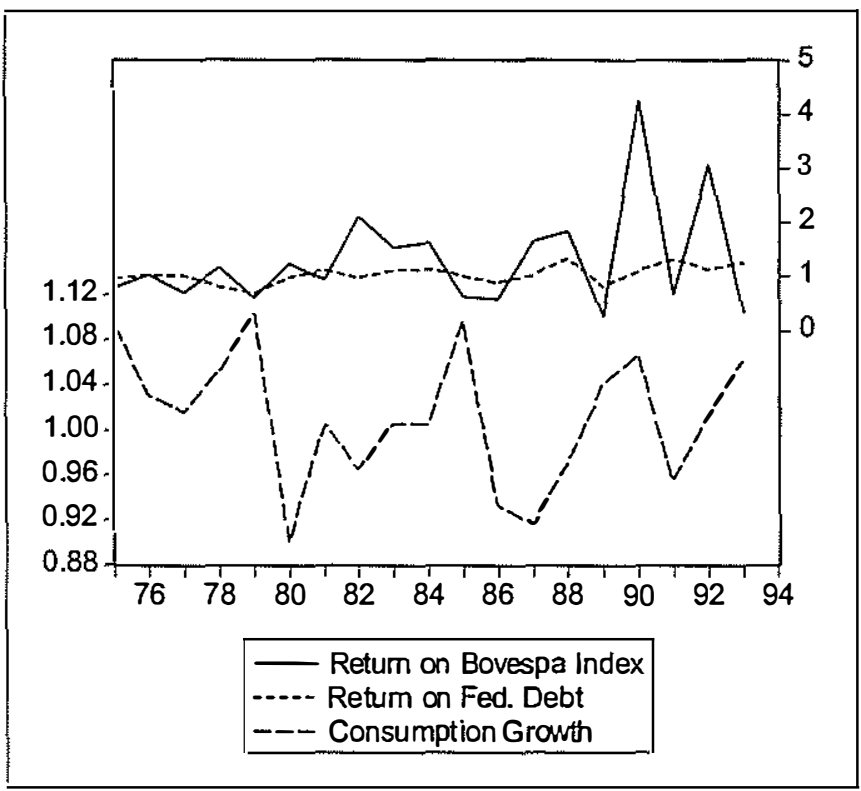

Figure 2: Data on Quarterly Frequency

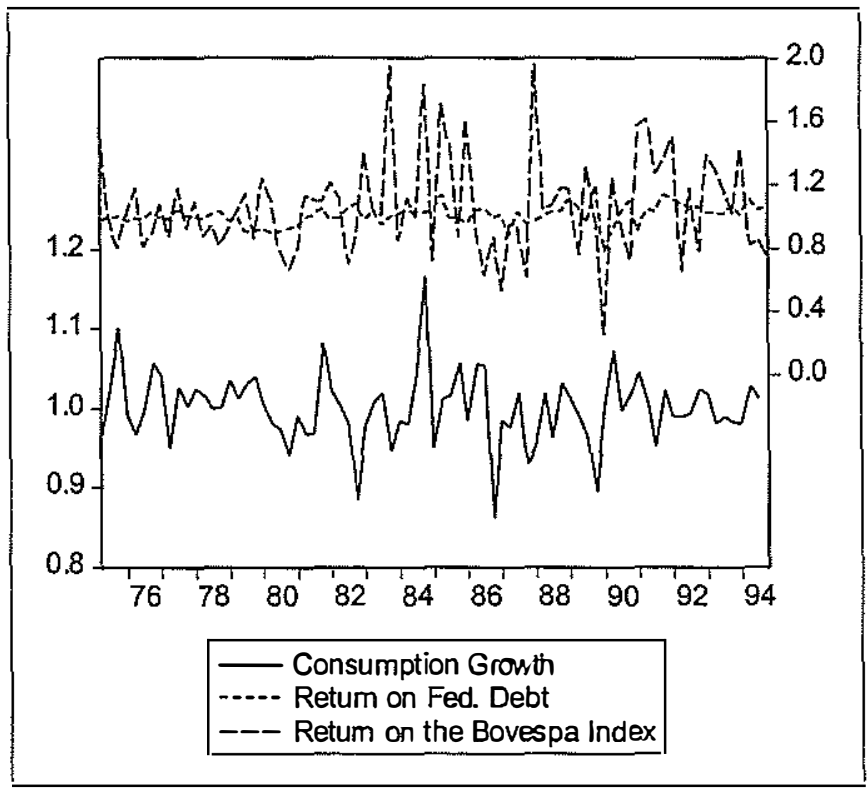




\subsection{GMM Estimation.}

The basic idea of estimation by the generalized method of moments is to implement a parameter estimation procedure, derived from some model (or not), that minimizes the sample analogue of the population orthogonality conditions (also known as moment restrictions). Estimation by instrumental variables might be viewed as an application of GMM, since it exploits the orthogonality between the residual and the instrument set.

Since GMM-estimate properties have been exhaustively discussed in the literature on applied econometrics and macroeconomics, it is not discussed here in any depth. As a reference for an introduction to the method, see Hamilton (1994), and Davidson and Mackinnon(1993). For a detailed explanation of GMM properties, see Hansen (1982), and for an explanation on the method's implementation and its representative consumer's (CRRA) basic macroeconomic model application see Hansen and Singleton (1982). For a fairly complete recent summary, see Matyas (1999).

To implement this technique we first select a set of instruments. To achieve robust results, different instrument sets are employed, following the previous literature. In order to identify the parameters of interest, there must be at least the same number of orthogonality conditions as the number of parameters. In general, models are overidentified (more orthogonality conditions than parameters), meaning that not all orthogonality conditions can be simultaneously satisfied at the optimum. Hence, a weighting matrix is used to construct a quadratic form which is then minimized. This weighting matrix can also be optimally estimated. To check the robustness of the results, different ways of estimating the optimum weighting matrix were used: the Newey and West (1987) method with a fixed window (denoted as F), the Newey and West (1994) method with a variable window (denoted as NWV) and the Andrews' (1991) method with a variable window (denoted as ADW). 
The correct specification of each model estimated by GMM is tested using the over-identifying restrictions test (see Hansen, 1982), the $(T \times J)$ statistics, which has a $\chi^{2}$ asymptotic distribution, with $(r-k)$ degrees of freedom, where $r$ is the number of orthogonality conditions and $k$ the number of parameters in the structural model.

\section{Empirical Results.}

In order to summarize the empirical results in the best possible way, we proceed here as follows: first, the results for the structural parameter estimates for each individual model are presented, with comparisons of the intra-model estimates performed in the next three sections. Second, all the empirical results are summarized and then inter-model estimates are compared, in order to have a clear picture of risk aversion, the inter-temporal discount rate, and inter-temporal substitution of consumption for Brazilian consumers. This is done in the fourth section, which also presents a comparison between the empirical results for Brazil with those for the U.S. economy. For the latter, we use as references Hansen and Singleton's $(1982,1984)$ results for CRRA utility with monthly data, Epstein and Zin(1991) results for Kreps-Porteus utility with monthly data, and Runkle (1991) results for CRRA utility with annual data.

\subsection{CRRA utility function model.}

The GMM estimate results for equation (9) are summarized in Tables 1a through 1c. Following Hansen and Singleton (1982) we estimated a system with two types of assets: a risk-free asset (government bonds) and a risky one (Bovespa index). Each Table presents the estimates obtained using different instrument sets and different ways of estimating the weightning matrix, as described in the previous section. It is important to notice that the convergence of the non-linear algorithm for the estimates was not achieved in all cases and our results list only results where convergence was achieved. 
Table 1: CRRA Utility - Euler Equation System

$$
1=E_{t}\left[\beta\left(\frac{C_{t+1}}{C_{t}}\right)^{-\gamma}\left(1+R_{i, t+1}\right)\right], \forall i=1, \ldots, N
$$

where $N=2$, and $R_{1, t+1}=$ Ibovespa Returns and $R_{2, t+1}=$ Returns on Government Bonds

(a)annual data

\begin{tabular}{llll}
\hline Inst./Mtx. & \multicolumn{1}{c}{$\beta$} & \multicolumn{1}{c}{$\gamma$} & $T \times J$ \\
\hline I4/F & $0.894^{* *}$ & $4.810^{* *}$ & 6.774 \\
& $(0.021)$ & $(0.238)$ & $(0.872)$ \\
I7/ADW & $0.890^{* *}$ & $4.970^{* *}$ & 10.200 \\
& $(0.04)$ & $(0.34)$ & $(0.598)$ \\
I8/ADW & $0.740^{* *}$ & $6.810^{* *}$ & 11.050 \\
& $(0.04)$ & $(1.09)$ & $(0.525)$ \\
I8/F & $0.830^{* *}$ & $6.600^{* *}$ & 6.630 \\
& $(0.03)$ & $(0.53)$ & $(0.881)$ \\
I7/F & $0.640^{* *}$ & $4.490^{* *}$ & 13.010 \\
& $(0.04)$ & $(0.66)$ & $(0.327)$ \\
I7/NWV & $0.900^{* *}$ & $6.820^{* *}$ & 9.010 \\
& $(0.04)$ & $(0.31)$ & $(0.702)$ \\
I4/NWV & $0.890^{* *}$ & $5.790^{* *}$ & 6.800 \\
& $(0.02)$ & $(0.27)$ & $(0.871)$ \\
I9/ADW & $1.010^{* *}$ & 1.360 & 4.76 \\
& $(0.03)$ & $(1.48)$ & $(0.575)$ \\
I9/F & $0.990^{* *}$ & 0.590 & 4.42 \\
& $(0.02)$ & $(1.33)$ & $(0.620)$ \\
I9/NWV & $1.000^{* *}$ & $2.640^{*}$ & 4.08 \\
& $(0.02)$ & $(1.37)$ & $(0.666)$ \\
Median & 0.89 & 4.89 & \\
Estimates & & & \\
\hline
\end{tabular}

Notes: (1) Inst. refers to the employed list of instruments. All of them contain a constant. In addition Il uses $R_{1, t+1}$ and $C_{t+1} / C_{t}$ lagged two periods, I2 uses $R_{2, t+1}$ and $C_{t+1} / C_{t}$ lagged two periods, I3 uses $R_{1, t}$ and $C_{t} / C_{t-1}$ lagged two periods, I4 uses $R_{1, t}, R_{2, t}$ and $C_{t} / C_{t-1}$ lagged two periods, I5 uses $R_{2, t}$ and $C_{t} / C_{t-1}$ lagged two periods, I6 uses $R_{1, t+1}, R_{2, t+1}$ and $C_{t+1} / C_{t}$ lagged two periods, 17 uses $R_{1, t+1}$ and $R_{2, t+1}$ lagged three periods, I8 uses $R_{1, t-1}, R_{2, t-1}$ and $C_{t-1} / C_{t-2}$ lagged two periods, I9 uses $C_{t+1} / C_{t}$ lagged two periods, I10 uses $R_{1, t+1}$ and $C_{t+1} / C_{t}$ lagged one period, Ill uses $R_{1, t}$ and $C_{t} / C_{t-1}$ lagged one period. 
(continued) Table 1: CRRA Utility - Euler Equation System

(b) seasonally adjusted quarterly data

\begin{tabular}{llll}
\hline Inst./Mtx. & \multicolumn{1}{c}{$\gamma$} & \multicolumn{1}{c}{$\gamma$} & $T \times J$ \\
\hline I3/F & $0.995^{* *}$ & $0.891^{* *}$ & 6.468 \\
& $(0.008)$ & $(0.701)$ & $(0.594)$ \\
I3/NWV & $0.993^{* *}$ & $1.255^{* *}$ & 5.700 \\
& $(0.041)$ & $(0.618)$ & $(0.680)$ \\
I3/ADW & $0.991^{* *}$ & 0.856 & 7.768 \\
& $(0.008)$ & $(0.789)$ & $(0.456)$ \\
I4/F & $0.981^{* *}$ & -0.589 & 9.978 \\
& $(0.006)$ & $(0.394)$ & $(0.617)$ \\
I4/NWV & $0.982^{* *}$ & $0.566^{*}$ & 7.192 \\
& $(0.005)$ & $(0.316)$ & $(0.844)$ \\
I4/ADW & $0.987^{* *}$ & 0.700 & 15.107 \\
& $(0.007)$ & $(0.612)$ & $(0.235)$ \\
I6/F & $0.993^{* *}$ & 0.311 & 10.373 \\
& $(0.005)$ & $(0.507)$ & $(0.583)$ \\
I6/NWV & $1.000^{* *}$ & 0.125 & 7.592 \\
& $(0.005)$ & $(0.423)$ & $(0.816)$ \\
I6/ADW & $0.986 * *$ & 0.146 & 18.065 \\
I7/F & $(0.006)$ & $(0.509)$ & $(0.113)$ \\
& $0.986^{* *}$ & 0.677 & 10.108 \\
I7/NWV & $(0.007)$ & $(0.518)$ & $(0.606)$ \\
I7/ADW & $0.992^{* *}$ & 0.399 & 7.335 \\
Median & $(0.007)$ & $(0.402)$ & $(0.834)$ \\
Estimates & $0.988^{* *}$ & $2.202^{*}$ & 11.539 \\
\hline
\end{tabular}

In the estimates with seasonal dummies, these were also included as instruments in the previous lists, though we kept the previous notation. (2) MItx. refers to how the moment's restrictions variance co-variance matrix was estimated, where $F$ denotes the use of the Newey and West (1994) technique with fixed window, ADW denotes the use of the Andrews (1991) technique with variable window, and NWV denotes the use of the Newey and West (1994) technique with variable window. 
(continued) Table 1: CRRA Utility - Euler Equation System

(c)quarterly data with seasonal dummies

\begin{tabular}{llll}
\hline Inst./Mtz. & \multicolumn{1}{c}{$\beta$} & \multicolumn{1}{c}{$\gamma$} & $T \times J$ \\
\hline I3/F & $0.978^{* *}$ & $1.320^{* *}$ & 10.129 \\
& $(0.017)$ & $(0.485)$ & $(0.518)$ \\
I3/ADW & $0.984^{* *}$ & $1.287^{* *}$ & 10.658 \\
& $(0.022)$ & $(0.513)$ & $(0.472)$ \\
I4/F & $0.968^{* *}$ & $1.373^{* *}$ & 11.295 \\
& $(0.016)$ & $(0.335)$ & $(0.731)$ \\
I4/NWD & $0.970^{* *}$ & $1.739^{* *}$ & 9.323 \\
& $(0.013)$ & $(0.300)$ & $(0.860)$ \\
I4/ADW & $0.979^{* *}$ & $1.176^{* *}$ & 13.748 \\
& $(0.020)$ & $(0.402)$ & $(0.544)$ \\
I6/F & $0.963^{* *}$ & $2.2284^{* *}$ & 12.267 \\
& $(0.024)$ & $(0.621)$ & $(0.658)$ \\
I6/ADW & $0.961^{* *}$ & $1.6826^{* *}$ & 15.244 \\
& $(0.024)$ & $(0.565)$ & $(0.433)$ \\
I7/F & $0.819^{* *}$ & $4.7902^{* *}$ & 10.266 \\
& $(0.045)$ & $(1.443)$ & $(0.802)$ \\
I7/N.WV & $0.776^{* *}$ & $6.4381^{* *}$ & 8.957 \\
& $(0.042)$ & $(1.369)$ & $(0.879)$ \\
I7/ADW & $0.843^{* *}$ & $3.9593^{* *}$ & 11.656 \\
& $(0.047)$ & $(1.499)$ & $(0.704)$ \\
Median & & & \\
Estimates & 0.97 & 1.70 & \\
\hline
\end{tabular}

(3) The numbers in parentheesis, below each parameter estimate, are the respective standarddeviation estimates, robust to heterocedasticity and to serial correlation of the moment's restrictions. (4) Hansen's (1982) over-identifying restrictions test statistic $T \times J$ and its p-value are respectively presented in the last column of each system estimate set. (5) The last line on the table represents the median estimate for each group of estimates. (6) ${ }^{*}$ and ${ }^{* *}$ denote, respectively, significance of parameters in a one sided $t$-test at the $5 \%$ and $1 \%$ levels. 
The results in tables 1a through 1c show that the system of Euler equations was not rejected by the $T \times J$ over-identifying restrictions test in any case, at the usual significance levels. The estimates for $\beta$ are, in general, very close to one (with a median of 0.99) for quarterly data, although close to 0.9 for annual data. Note that estimates for different time frequencies are only comparable if these were normalized to a common time frequency, which corresponds to a quarterly estimate of 0.96 in an annual basis.

The estimates for $\gamma$ are less robust, especially if we compare the results between tables $1 \mathrm{~b}$ and $1 \mathrm{c}$. For the former, we have positive estimates between zero and one, but (with a few exceptions) not significantly different from zero. For the latter, we have estimates above one and significant in all cases. If we only consider results from table 1c we would have a risk aversion coefficient of approximately 1.70 , which seems reasonable a priori. The existence of no risk neutrality $(\gamma>0)$ obtained in table 1c is consistent with results of table 1a. However, the result for annual data reveals a risk aversion almost three times bigger than the average estimate for quarterly data with seasonal dummies (4.89).

Given that, for both annual and quarterly estimates (with seasonally adjusted dummies) relatively high values for $\gamma$ were obtained with CRRA utility function, we conclude that relative risk aversion is high for Brazilian consumers. In that sense, the seasonally adjusted quarterly results, which reveal a median risk aversion estimate of 0.62 , would be an exception. It should be emphasized that Hansen and Singleton used similar seasonally adjusted data, a reason for which we should not dismiss this last result here ${ }^{9}$.

\footnotetext{
${ }^{9}$ In light of the results with annual data, and considering that the only difference between the quarterly data results is the way of modeling seasonality, we may conclude that the use of seasonally adjusted series captures part of the cyclical growth variation of asset consumption and return. If this were the case, it would be preferable to use seasonal dummies to isolate the seasonal aspect of the data. If we compare table 1c with Reis et alli (1998), who also use seasonal dummies,
} 


\subsection{External Habit Model.}

Tables $2 \mathrm{a}$ and $2 \mathrm{~b}$ summarize the main results of the estimation of the system of Euler equations (for both the risk-free and risky assets) given by (15) - in annual and quarterly frequency (seasonally adjusted data) ${ }^{10}$. The notation followed is the same as in previous tables, with small variations regarding the instrument set.

Results in table 2 are ambiguous, even thought the external habit model is not rejected in any case by the over-identifying restriction tests $^{11}$. The reason for this ambiguity is the fact that we found strong evidence that $\kappa=0$ for quarterly data and that $\kappa \neq 0$ for annual data. Moreover, in most of the cases, we found two types of counterintuitive results that violate at least one of the external-habit model basic assumptions. The first is that $\kappa<0$, and, at the same time $\gamma>$ 0 , and the second is that $\kappa>0$, and, at the same time $\gamma>0$. Notice that there is no such case in which the estimates for both are positive and individually significant. Anyway, the median estimate for $\gamma$ is 1.10 , which seems reasonable. The annual results for $\beta$ indicate a median estimate of 0.88 , which seems reasonable, but rather low. The inter-temporal elasticity of substitution in consumption $\psi$ (still equal to $1 / \gamma$ ) has a median of 0.91 for annual data.

\footnotetext{
fairly similar results are obtained, with a non-trivial estimate for the inter-temporal substitution in consumption. Even so, the estimates for $\beta$ in Reis et alli are considerably lower than ours.

${ }^{10}$ This model was not estimated using seasonal dummies, only with seasonally adjusted data, which would be interesting for the purpose of comparison with Reis et alli's results

${ }^{11}$ It is worth noting that, with annual data, achieving convergence for the GMI estimation code was extremely difficult.
} 
Table 2: External Habit Utility - Euler Equation System

$$
1=E_{t}\left[\beta\left(\frac{C_{t}}{C_{t-1}}\right)^{\kappa(\gamma-1)}\left(\frac{C_{t+1}}{C_{t}}\right)^{-\delta}\left(1+R_{i, t+1}\right)\right], \forall i=1, \ldots, N
$$

where $N=2$, and $R_{1, t+1}=$ Ibovespa Returns and $R_{2, t+1}=$ Returns on Government Bonds
(a)annual data

\begin{tabular}{lllll}
\hline Inst./Mtx. & \multicolumn{1}{c}{$\beta$} & \multicolumn{1}{c}{$\kappa$} & \multicolumn{1}{c}{$\gamma$} & $T \times J$ \\
\hline I4/ADW & $1.044^{* *}$ & $-0.792^{*}$ & $-0.709^{* *}$ & 9.204 \\
& $(0.010)$ & $(0.423)$ & $(0.458)$ & $(0.603)$ \\
I8/ADW & $0.751^{* *}$ & $-0.601^{* *}$ & $12.993^{* *}$ & 7.140 \\
& $(0.060)$ & $(0.167)$ & $(2.227)$ & $(0.787)$ \\
I4/NWV & $0.860^{* *}$ & $-0.350^{* *}$ & $3.390^{* *}$ & 5.280 \\
& $(0.01)$ & $(0.10)$ & $(0.17)$ & $(0.917)$ \\
I4/F & $0.920^{* *}$ & $-11.88^{* *}$ & $1.00^{* *}$ & 6.400 \\
& $(0.01)$ & $(0.03)$ & $(0.12)$ & $(0.845)$ \\
I4" /F & $0.820^{* *}$ & $0.570^{* *}$ & $-1.600^{* *}$ & 6.560 \\
& $(0.03)$ & $(0.29)$ & $(1.60)$ & $(0.833)$ \\
I4" /NWV & $0.870^{* *}$ & $0.660^{* *}$ & $-0.65^{* *}$ & 4.800 \\
& $(0.01)$ & $(0.28)$ & $(0.72)$ & $(0.940)$ \\
I7/NWV & $0.890^{* *}$ & $-0.520^{* *}$ & $60.28^{* *}$ & 6.29 \\
& $(0.09)$ & $(0.04)$ & $(0.90)$ & $(0.901)$ \\
I11/F & $1.04^{* *}$ & 3.58 & 1.19 & 2.89 \\
& $(0.03)$ & $(45.57)$ & $(2.32)$ & $(0.409)$ \\
Median & 0.88 & -0.44 & 1.10 & \\
Estimates & 0.88 &
\end{tabular}

Notes: (1) Inst. refers to the utilized instrument list. All of them contain a constant. In addition I1 uses $R_{1, t+1}$ and $C_{t+1} / C_{t}$ lagged two periods, I2 uses $R_{2, t+1}$ and $C_{t+1} / C_{t}$ lagged two periods, I3 uses $R_{1, t}$ and $C_{t} / C_{t-1}$ lagged two periods, I4 uses $R_{1, t}, R_{2, t}$ and $C_{t} / C_{t-1}$ lagged two periods, I5 uses $R_{2, t}$ and $C_{t} / C_{t-1}$ lagged two periods, I6 uses $R_{1, t+1}, R_{2, t+1}$ and $C_{t+1} / C_{t}$ lagged two periods, 17 uses $R_{1, t+1}$ and $R_{2, t+1}$ lagged three periods, I8 uses $R_{1, t-1}, R_{2, t-1}$ and $C_{t-1} / C_{t-2}$ lagged two periods, I9 uses $C_{t+1} / C_{t}$ lagged two periods, I10 uses $R_{1, t+1}$ and $C_{t+1} / C_{t}$ lagged one period, I11 uses $R_{1, t}$ and $C_{t} / C_{t-1}$ lagged one period. In some cases, we used these same generic instrument sets (IJ) with an additional lag for the consumption growth rate, denoted as IJ". (2) Mtx. refers to how the momments restrictions variance co-variance matrix was estimated, where the symbol $F$ denotes the use of the Newey and West (1994) technique with fixed window, ADW denotes the use of the Andrews (1991) technique with variable window, and NWV denotes the use of the Newey and West (1994) technique with variable window. 
(continued) Table 2: External Habit - Euler Equation System

(b) seasonally adjusted quarterly data

\begin{tabular}{|c|c|c|c|c|}
\hline Inst./Mtx. & $\beta$ & $\kappa$ & $\gamma$ & $T \times J$ \\
\hline $\mathrm{I1} " / \mathrm{F}$ & $\begin{array}{l}1.004^{* *} \\
(0.009)\end{array}$ & $\begin{array}{l}2.894 * * \\
(0.566)\end{array}$ & $\begin{array}{l}0.614 \\
(0.591)\end{array}$ & $\begin{array}{l}5.332 \\
(0.619)\end{array}$ \\
\hline I1" / ADW & $\begin{array}{l}0.995^{* *} \\
(0.009)\end{array}$ & $\begin{array}{l}3.280 \\
(6.77)\end{array}$ & $\begin{array}{l}0.695 \\
(0.620)\end{array}$ & $\begin{array}{l}6.516 \\
(0.480)\end{array}$ \\
\hline $\mathrm{I} 4 / \mathrm{F}$ & $\begin{array}{l}0.987 * * \\
(0.007)\end{array}$ & $\begin{array}{l}1.190 \\
(1.112)\end{array}$ & $\begin{array}{l}0.492 \\
(0.370)\end{array}$ & $\begin{array}{l}9.094 \\
(0.613)\end{array}$ \\
\hline I4/NWV & $\begin{array}{l}0.991 * * \\
(0.006)\end{array}$ & $\begin{array}{l}0.679 \\
(0.454)\end{array}$ & $\begin{array}{l}0.436 \\
(0.285)\end{array}$ & $\begin{array}{l}7.130 \\
(0.788)\end{array}$ \\
\hline I4/ADW & $\begin{array}{l}0.987^{* *} \\
(0.08)\end{array}$ & $\begin{array}{l}3.442 \\
(11.89)\end{array}$ & $\begin{array}{l}0.833 \\
(0.579)\end{array}$ & $\begin{array}{l}13.172 \\
(0.282)\end{array}$ \\
\hline $\mathrm{I} 4 " \mathrm{~F}$ & $\begin{array}{l}0.979^{* * *} \\
(0.008)\end{array}$ & $\begin{array}{l}3.655 \\
(16.25)\end{array}$ & $\begin{array}{l}0.815 \\
(0.529)\end{array}$ & $\begin{array}{l}8.416 \\
(0.675)\end{array}$ \\
\hline I4" /NWV & $\begin{array}{l}0.979 * * \\
(0.007)\end{array}$ & $\begin{array}{l}0.584 \\
(0.520)\end{array}$ & $\begin{array}{l}0.410 \\
(0.484)\end{array}$ & $\begin{array}{l}7.625 \\
(0.746)\end{array}$ \\
\hline I6" / F & $\begin{array}{l}0.998 * * \\
(0.007)\end{array}$ & $\begin{array}{l}1.533 \\
(1.350)\end{array}$ & $\begin{array}{l}0.413 \\
(0.376)\end{array}$ & $\begin{array}{l}9.663 \\
(0.560)\end{array}$ \\
\hline I6" /NWV & $\begin{array}{l}1.00 *^{* *} \\
(0.005)\end{array}$ & $\begin{array}{l}0.524 \\
(0.533)\end{array}$ & $\begin{array}{l}0.498^{*} \\
(0.278)\end{array}$ & $\begin{array}{l}6.787 \\
(0.816)\end{array}$ \\
\hline I6" / ADW & $\begin{array}{l}0.988 * * \\
(0.007)\end{array}$ & $\begin{array}{l}1.563 \\
(2.46)\end{array}$ & $\begin{array}{l}0.654 \\
(0.472)\end{array}$ & $\begin{array}{l}14.321 \\
(0.215)\end{array}$ \\
\hline I7/NWV & $\begin{array}{l}0.956 * * \\
(0.032)\end{array}$ & $\begin{array}{l}3.212 \\
(2.206)\end{array}$ & $\begin{array}{l}2.617^{*} \\
(1.484)\end{array}$ & $\begin{array}{l}6.537 \\
(0.835)\end{array}$ \\
\hline $\mathrm{I} 8 / \mathrm{F}$ & $\begin{array}{l}0.984^{* *} \\
(0.007)\end{array}$ & $\begin{array}{l}0.694 \\
(0.526)\end{array}$ & $\begin{array}{l}-0.687 \\
(0.799)\end{array}$ & $\begin{array}{l}10.648 \\
(0.473)\end{array}$ \\
\hline I8/ADW & $\begin{array}{l}0.986^{* *} \\
(0.006)\end{array}$ & $\begin{array}{l}3.730 * * \\
(0.521)\end{array}$ & $\begin{array}{l}-0.336 \\
(0.69)\end{array}$ & $\begin{array}{l}13.421 \\
(0.266)\end{array}$ \\
\hline $\mathrm{I} 10^{\prime \prime} / \mathrm{F}$ & $\begin{array}{l}0.994^{* * *} \\
(0.008)\end{array}$ & $\begin{array}{l}0.745 \\
(1.102)\end{array}$ & $\begin{array}{l}0.192 \\
(0.580)\end{array}$ & $\begin{array}{l}2.404 \\
(0.492)\end{array}$ \\
\hline I10" / NWV & $\begin{array}{l}0.998^{* *} \\
(0.009)\end{array}$ & $\begin{array}{l}0.967 \\
(1.386)\end{array}$ & $\begin{array}{l}0.302 \\
(0.594)\end{array}$ & $\begin{array}{l}2.424 \\
(0.489)\end{array}$ \\
\hline I10" / ADW & $\begin{array}{l}0.992 * * \\
(0.007)\end{array}$ & $\begin{array}{l}0.571 \\
(0.424)\end{array}$ & $\begin{array}{l}-0.028 \\
(0.590)\end{array}$ & $\begin{array}{l}2.359 \\
(0.501)\end{array}$ \\
\hline $\begin{array}{l}\text { Median } \\
\text { Estimates }\end{array}$ & 0.99 & 1.36 & 0.46 & \\
\hline
\end{tabular}

(3) The numbers in parenthesis, below each parameter estimates are the respective standarddeviation estimates, robust to heterocedasticity and to correlation of the moments restrictions. (4) Hansen's (1982) over-identifying restrictions test statistic $T \times J$ and its p-value are respectively presented in the last column of each system estimate set. (5) The last line on the table represents the median estimate for each group of estimates. (6) * and ** denote, respectively, significance of parameters in a one sided $t$-test at the $5 \%$ and $1 \%$ levels. 
For quarterly data, sensible estimates for $\beta$ are found in most cases. However, for $\gamma$ and $\kappa$ we find evidence that these are individually zero, with rare exceptions. Recall that, when $\kappa=0$, the external habit model degenerates into the CRRA utility model. Notice that there are some exceptions where we find evidence of non-separability over time; see table $2 \mathrm{~b}$. In these cases, given the respective $\gamma$ estimates, we would conclude that agents are risk neutral. However, the majority of the quarterly results on table $2 \mathrm{~b}$ show a strong sign of separability (i.e. $\kappa=0$ ). In this case, $\gamma$ estimates in table 1 would be more efficient than those in table 2 , because in the CRRA utility model has one less parameter than the external habit model.

\subsection{Kreps-Porteus utility type model.}

In Epstein and Zin's original work (1991), estimation of the system of Euler equations given by (21) and (23) was conducted using five assets: the risk-free asset (government bonds) and four groups of sectoral portfolio shares. However, a series on IBOVESPA returns disaggregated by sector is not available. Hence, we only estimate the parameters for the risk-free asset. The instrument sets are the same of those of the previous models (noting that in most of the cases the convergence of estimates was not achieved).

The choice of parameters to be directly estimated for the combined system (21) and (23), was ( $\beta, \eta$ and $\rho$ ), given that, this choice better suited the numerical methods employed here. Since the parameters of interest are $\beta, \psi$ and $\gamma^{12}$, the estimates for $\psi$ and $\gamma$ were obtained from $\widehat{\eta}$ and $\hat{\rho}$ using the Delta Method (see Greene (1997)).

\footnotetext{
${ }^{12}$ The $\eta$ parameter interpretation was done in the original work, reflecting the agent's preference for a "late" or "recent" resolution of uncertainty.
} 
For quarterly data (table $3 \mathrm{~b}$ ), the over-identifying restrictions tests did not reject the model for instrument sets: I3, I4, I7, I9, and I10. In the cases where the model was not rejected, the estimates of $\beta$ were significant and high, varying between 0.94 and 0.98 - with a median estimate of 0.96 . In most of these cases, the estimates for $\psi$ were significantly different from 0 , between $[0.2,0.3]$ (median 0.29). These estimates show that agents have some disposition in altering their consumption patterns when facing variations of the interest rate, i.e. some inter-temporal substitution in consumption. In most of the cases where the model was not rejected, we found that $\gamma$ was statistically significant, which would lead us to a model with expected utility and logarithmic preference. The median estimate for $\gamma$ was 0.68 .

The convergence of estimates, for annual data (table 3a), was obtained in fewer cases and for fewer instrument sets. A median estimate of 0.93 was obtained for $\beta$, although some estimates reached values above one (I6-F). In most of the cases the parameter $\psi$ was significantly different from 0 , with a median estimate of 0.24 , a value close to that for quarterly data. The parameter $\psi$ was statistically different from zero in four cases, from a total of 9. This is more evidence favoring a model with expected utility and logarithmic preferences, the median estimate of $\gamma$ being 0.75 . 
João Victor Issler and Natalia Scotto Piqueira

Table 3: Kreps-Porteus Utility - Euler Equations System

$$
\left\{\begin{array}{l}
1=E_{t}\left[\beta^{\eta}\left(\frac{C_{t+1}}{C_{t}}\right)^{\eta(\rho-1)} \widetilde{B}_{t+1}^{\eta-1}\left(1+R_{i, t+1}\right)\right], \forall i=1, \ldots, N \\
E_{t}\left[\frac{\left[\beta\left(\frac{C_{t+1}}{C_{t}}\right)^{(\rho-1)} \widetilde{B}_{t+1}\right]^{\eta}-1}{\eta}\right]=0
\end{array}\right.
$$

where $N=1$, and $\widetilde{B}_{t+1}=$ Ibovespa Returns and $R_{1, t+1}=$ Returns on Government Bonds, $\eta=\frac{\alpha}{\rho}, \psi=\frac{1}{1-\rho}, \gamma=1-\alpha$.

(a)annual data

\begin{tabular}{llllll}
\hline Inst./Mtx. & \multicolumn{1}{c}{$\beta$} & \multicolumn{1}{c}{$\rho$} & \multicolumn{1}{c}{$\psi$} & \multicolumn{1}{c}{$\gamma$} & $T \times J$ \\
\hline I4/NWV & $0.934^{* *}$ & $1.521^{* *}$ & $-1.919^{* *}$ & 0.032 & 5.185 \\
& $(0.008)$ & $(0.256)$ & $(0.953)$ & $(0.175)$ & $(0.921)$ \\
I9/F & $0.931^{* *}$ & -3.192 & 0.238 & $2.797^{*}$ & 1.619 \\
& $(0.005)$ & $(3.562)$ & $(0.202)$ & $(1.579)$ & $(0.655)$ \\
I9/ADW & $0.932^{* *}$ & -3.185 & 0.238 & -0.802 & 1.615 \\
& $(0.059)$ & $(3.563)$ & $(0.203)$ & $(1.595)$ & $(0.655)$ \\
I10/ADW & $0.820^{* *}$ & $10.567^{* *}$ & $-0.104^{* *}$ & $-27.23^{* *}$ & 2.61 \\
& $(0.104)$ & $(2.878)$ & $(0.031)$ & $(8.735)$ & $(0.455)$ \\
I11/F & $1.020^{* *}$ & -0.289 & 0.775 & 1.308 & 2.403 \\
& $(0.05)$ & $(1.870)$ & $(1.125)$ & $(1.998)$ & $(0.493)$ \\
I11/NWV & $0.975^{* *}$ & -2.839 & $0.260^{* *}$ & $3.083^{* *}$ & 1.989 \\
& $(0.053)$ & $(16.25)$ & $(0.124)$ & $(1.27)$ & $(0.544)$ \\
I9/F & $0.94^{* *}$ & -3.180 & 0.240 & 2.780 & 1.800 \\
& $(0.06)$ & $(3.55)$ & $(0.20)$ & $(1.92)$ & $(0.610)$ \\
I6/F & $1.19^{* *}$ & $0.130^{* *}$ & $1.149^{* *}$ & 0.750 & 6.120 \\
I6/NWV & $(0.03)$ & $(0.41)$ & $(0.54)$ & $(0.79)$ & $(0.865)$ \\
& $0.81^{* *}$ & $4.390^{* *}$ & $-2.94^{* *}$ & $-5.360^{* *}$ & 17.46 \\
Median & $(0.02)$ & $(0.74)$ & $(0.06)$ & $(1.08)$ & $(0.095)$ \\
Estimates & 0.93 & & & & \\
\hline
\end{tabular}

Notes: (1) Inst. refers to the employed instrument list. All of them contain a constant. In addition I1 uses $R_{1, t+1}$ and $C_{t+1} / C_{t}$ lagged two periods,I2 uses $\widetilde{B}_{t+1}$ and $C_{t+1} / C_{t}$ lagged two periods, I3 uses $R_{1, t}$ and $C_{t} / C_{t-1}$ lagged two periods, I4 uses $R_{1, t}, \widetilde{B}_{t}$ and $C_{t} / C_{t-1}$ lagged two periods, 15 uses $\widetilde{B}_{t}$ and $C_{t} / C_{t-1}$ lagged two periods, I6 uses $R_{1, t+1}, \widetilde{B}_{t+1}$ and $C_{t+1} / C_{t}$ lagged two periods, $I 7$ uses $R_{1, t+1}$ and $\widetilde{B}_{t+1}$ lagged three periods, I8 uses $R_{1, t-1}, \widetilde{B}_{t-1}$ and $C_{t-1} / C_{t-2}$ lagged two periods, I9 uses $C_{t+1} / C_{t}$ lagged two periods, I10 uses $R_{1, t+1}$ and $C_{t+1} / C_{t}$ lagged one period, I11 uses $R_{1, t}$ and $C_{t} / C_{t-1}$ lagged one period. 
Risk Aversion, Discount Rate

(continued) Table 3: Kreps-Porteus Utility - Euler Equations System

(b) seasonally adjusted quarterly data

\begin{tabular}{llllll}
\hline Inst./Mtx. & \multicolumn{1}{c}{$\beta$} & \multicolumn{1}{c}{$\rho$} & \multicolumn{1}{c}{$\psi$} & \multicolumn{1}{c}{$\gamma$} & $T \times J$ \\
\hline I2/ADW & $0.947^{* *}$ & $2.439^{* *}$ & $-0.694^{* *}$ & 1.151 & 15.76 \\
& $(0.010)$ & $(0.747)$ & $(0.114)$ & $(0.192)$ & $(0.027)$ \\
I3/F & $0.946^{* *}$ & $-2.473^{*}$ & $0.287^{* *}$ & $-0.271^{*}$ & 8.85 \\
& $(0.020)$ & $(1.408)$ & $(0.116)$ & $(1.07)$ & $(0.263)$ \\
I3/NWV & $0.949^{* *}$ & $-2.447^{* *}$ & $0.290^{* *}$ & -0.262 & 7.717 \\
& $(0.020)$ & $(1.27)$ & $(0.107)$ & $(0.921)$ & $(0.358)$ \\
I4/F & $0.960^{* *}$ & $-2.477^{* *}$ & $0.287^{* *}$ & $-1.137^{* *}$ & 10.725 \\
& $(0.020)$ & $(1.17)$ & $(0.096)$ & $(1.158)$ & $(0.151)$ \\
I4/NWV & $0.985^{* *}$ & -1.166 & $0.375^{* *}$ & -0.699 & 8.662 \\
& $(0.019)$ & $(0.904)$ & $(0.127)$ & $(1.986)$ & $(0.653)$ \\
I4/ADW & $0.946^{* *}$ & -1.206 & $0.453^{* *}$ & $-0.111^{* *}$ & 18.15 \\
& $(0.019)$ & $(1.108)$ & $(0.227)$ & $(1.008)$ & $(0.078)$ \\
I7/F & $0.966^{* *}$ & -2.207 & $0.311^{* *}$ & $0.802^{* *}$ & 6.590 \\
& $(0.016)$ & $(1.340)$ & $(0.122)$ & $(0.223)$ & $(0.831)$ \\
I7/AWD & $0.969^{* *}$ & $-2.475^{* *}$ & $0.287^{* *}$ & 1.193 & 7.524 \\
& $(0.018)$ & $(1.665)$ & $(0.137)$ & $(0.453)$ & $(0.755)$ \\
I9/F & $0.961^{* *}$ & $1.517^{* *}$ & -1.934 & $0.676^{* *}$ & 1.694 \\
& $(0.018)$ & $(0.666)$ & $(2.497)$ & $(0.349)$ & $(0.638)$ \\
I9/NWV & $0.964^{* *}$ & $1.401^{* *}$ & $-2.493^{* *}$ & $-0.632^{* *}$ & 1.740 \\
& $(0.017)$ & $(0.665)$ & $(4.204)$ & $(0.305)$ & $(0.628)$ \\
I9/ADW & $0.960^{* *}$ & $1.676^{* *}$ & -1.477 & 0.644 & 1.725 \\
& $(0.018)$ & $(0.730)$ & $(1.595)$ & $(0.452)$ & $(0.631)$ \\
I10/ADW & $0.963^{* *}$ & -1.408 & 0.415 & 1.516 & 0.808 \\
& $(0.025)$ & $(6.38)$ & $(1.100)$ & $(2.356)$ & $(0.847)$ \\
I11/F & $0.957^{* *}$ & -0.033 & 0.968 & 0.975 & 7.242 \\
Median & $(0.020)$ & $(1.092)$ & $(1.168)$ & $(0.834)$ & $(0.064)$ \\
Estimates & 0.96 & & & & \\
\hline
\end{tabular}

Notes: (2) Mitx. refers to how the moment's restrictions variance co-variance matrix was estimated, where the symbol $F$ denotes the use of the Newey and West (1994) technique with fixed window, ADW denotes the use of the Andrews (1991) technique with variable window, and NWV denotes the use of the Newey and West (1994) technique with variable window. (3) The numbers in parenthesis below the parameter estimates are the respective standard-deviation estimates, robust to heterocedasticity and to serial correlation of the moment's restrictions. (4) Hansen's (1982) over-identifying restrictions test statistic $T \times J$ and its p-value are showed in the last column of each system estimate set. (5) The last line on the table represents the median estimate for each group estimates. $(6)^{*}$ and ${ }^{* *}$ denote, respectively, significance of parameters in a one sided $t$-test at the $5 \%$ and $1 \%$ levels. 
The idea behind using the Kreps-Porteus utility function to solve the U.S.equity premium puzzle is that of adding more noise to the pricing kernel (via the inclusion of the aggregate uncertainty term) to generate a higher co-variance (in absolute terms) with the assets return rate, given that, the aggregate consumption series is very smooth. The above results show that, for Brazilian data, the KrepsPorteus utility type model is not capable of altering the basic model's results. First, because it is not applicable to some instrument sets (over-identifying restrictions tests). Second, because it shows evidence of non-rejection of risk neutrality. The major benefit of using this type of specification refers to the dissociation between the intertemporal elasticity of substitution estimate and the risk aversion coefficient. Here, the estimates for the first were relatively low - a median elasticity of 0.24 for annual data and 0.29 for quarterly data. Also notice that these values are in line with similar results using power utility (CRRA) - median of 0.21 .

\subsection{Summarizing Brazilian results and comparing them with U.S. results.}

A summary of median Brazilian results using three types of utility function is presented in Table 4. The results for $\beta$ the discount rate are reported in terms of annual equivalent rate, in order to allow inter-model comparisons. The results can be summarized in the following way:

1. The estimates for the discount rate $\beta$ vary between 0.85 and 0.96 in an annual basis. Hence, for the Brazilian economy, a value of around 0.90 in annual basis would be reasonable.

2. The relative risk aversion coefficient estimates $\gamma$ were not robust, because there is strong evidence of risk neutrality, as well as of high risk aversion - estimates between 0.5 and 1 for neutrality and in the other case an extremely high median of 4.89. Therefore, 
it is difficcult to choose a representative value for the risk aversion coefficient of the Brazilian economy. Given the potential problem of using seasonally adjusted data (instead of seasonal dummies for the regressions) as discussed above, it may be preferable to use annual data results. These would point to a moderately high average relative risk aversion, coefficient between $\gamma=1.10$, for the external habit model and $\gamma=4.89$, for the CRRA utility model.

3. With the exception of the external habit models, the intertemporal substitution in consumption results point to an intertemporal elasticity $\psi$ that is low, predominately around 0.25 . Also, as in the case of relative risk aversion coefficient, there are some inconsistentencies between estimates.

The comparison between Brazilian and U.S. estimates are performed using tables 4 and 5 . It is preferable to compare results from equivalent models and identical time frequencies (or as close as possible, such as quarterly and monthly). After comparing results we conclude the following:

1. The Brazilian consumer is more impatient than the U.S. consumer, since the discount rate is higher for Brazil (close to 0.9) than for the U.S. (close to 1.0).

2. Brazilians are more risk averse than U.S. consumers, with risk aversion levels up to two to three times higher: 4.89 versus 0.62 and 0.62 versus 0.14 , depending on the time frequency of the data. An exception is accounted for in the results where Kreps-Porteus utility was used, where U.S. inhabitants have a higher risk aversion: 1.02 versus 0.64 . It is worth reporting that $\alpha$ was not significant in most of the estimates for Brazil and in Epstein and Zin(1991) for the U.S. Therefore, there might be no differences between Brazilian and U.S. consumers for the Kreps-Porteus specification.

3. Brazilians have an inter-temporal elasticity of substitution 
in consumption $\psi$ lower than that of U.S. consumers, with median values at least half of theirs: 0.21 versus $0.45,1.61$ versus 7.14 , and 0.29 versus 0.72 . This result is not surprising given the incipient Brazilian capital market in comparison to the international pattern (see liquidity-constraint in Reis et alli (1998)).

Table 4: Summary of Results for Brazil using Median Estimates

\begin{tabular}{|c|c|c|c|c|c|c|}
\hline & \multicolumn{2}{|c|}{ Annual data } & \multicolumn{4}{|c|}{ Seasonally Adjusted Quarterly Data } \\
\hline & \multicolumn{5}{|c|}{ BRAZIL } & \multirow[b]{2}{*}{$\begin{array}{l}\text { Kreps- } \\
\text { Porteus }\end{array}$} \\
\hline & CRRA & $\begin{array}{l}\text { External } \\
\text { Habit }\end{array}$ & $\begin{array}{l}\text { Kreps- } \\
\text { Porteus }\end{array}$ & CRRA & $\begin{array}{l}\text { External } \\
\text { Habit }\end{array}$ & \\
\hline$\beta$ (discount rate) & 0.890 & 0.880 & 0.930 & 0.960 & 0.960 & 0.850 \\
\hline$\gamma$ (relat.risk aversion) & 4.89 & 1.10 & 0.75 & 0.62 & 0.46 & 0.64 \\
\hline$\psi(\mathrm{IES})$ & 0.21 & 0.91 & 0.24 & 1.61 & 2.17 & 0.29 \\
\hline
\end{tabular}

Notes: the results hereby reported were extracted from tables 1,2 and 3. To allow the comparison of estimates in different $\beta$ frequencies, they were all transformed into the corresponding equivalent annual rates.

Table 5: Summary of Results for the USA using Median Estimates

\begin{tabular}{lclllll}
\hline & \multicolumn{7}{c}{ Annual data } & Seasonally Adjusted Monthly Data \\
\hline & \multicolumn{7}{c}{ U.S. A. } \\
\hline & CRRA & $\begin{array}{l}\text { External } \\
\text { Kreps- }\end{array}$ & CRRA & External Kreps- \\
& & Habit & Porteus & & Habit & Porteus \\
\hline$\beta$ (discount rate) & - & - & - & 0.995 & - & 0.980 \\
$\gamma$ (relat.risk aversion) 2.25 & - & - & 0.14 & - & 1.02 \\
$\psi$ (IES) & 0.45 & - & - & 7.14 & - & 0.72 \\
\hline
\end{tabular}

Notes: (1) To allow the comparison of estimates in different $\beta$ frequencies, they were all transformed into the corresponding equivalent annual rate. (2) The results using the CRRA function and annual data were extracted from Runkle (1991, Table 2, column 1). (3) The results using a CRRA function, for monthly data, were extracted from Hansen and Singleton (1984, Table 3, column 2). Note that that result was reported in an errata to the 1982 article. (4) The results using Kreps-Porteus utility and monthly data were extracted from Epstein and Zin (1991, table 4). 
Finally, it is worth discussing the existence or not of the equity premium puzzle, in the context of the Brazilian economy. The first formal econometric tests with Euler Equation systems were implemented by Hansen and Singleton (1982) on the CRRA utility model using Hansen's (1982) $T \times J$ test. Hansen and Singleton (1984, table 3 , column 2$)^{13}$ reported that, at the $5 \%$ significance level, system (9) is rejected for all possible instruments list (a total of six). These results were maintained even when varying the utility function, because Epstein and Zin (1991, table 4), using Kreps-Porteus utility, rejected the model in four occasions (out of six possible ones). Hence, there is weak empirical evidence for the validity of the restrictions implied by CCAPM for the U.S. economy.

For Brazil the opposite is true. In Hansen's $T \times J$ tests, virtually all models had a strong empirical support. The only exception was the Kreps-Porteus utility model, which was rejected in a small number of cases (4/22). Therefore, a conclusion emerging from our empirical results is that there is no equity premium puzzle for Brazil. Notice that this occurs regardless of utility function, the time frequency of the data, and the instrument list used, which makes this result relatively wide and robust.

Obviously, a detailed investigation of a Brazilian equity premium puzzle is beyond the scope of this article, nonetheless a preliminary investigation into the matter is appropriate. Let's suppose that for equation (9) two Brazilian assets are considered: returns from government bonds $R_{1 t}$ and returns from a stock index $R_{2 t}$. Combining both equations we have:

$$
0=E_{t}\left[\beta\left(\frac{C_{t+1}}{C_{t}}\right)^{-\gamma}\left(R_{2, t+1}-R_{1, t+1}\right)\right]
$$

${ }^{13}$ Note that this article is an errata of the 1982 original article. 
Taking the unconditional expectation of the above expression, using the Law of Iterated Expectations:

$$
0=E\left[\beta\left(\frac{C_{t+1}}{C_{t}}\right)^{-\gamma}\left(R_{2, t+1}-R_{1, t+1}\right)\right] .
$$

Now, if we knew the value for population parameters $\beta$ and $\gamma$ we could simply test if $\beta\left(\frac{C_{t+1}}{C_{t}}\right)^{-\gamma}\left(R_{2, t+1}-R_{1, t+1}\right)$ was zero on average, which is a simple statistical test.

Although we do not know the population values for $\beta$ and $\gamma$, we will use here in this preliminary investigation their respective median values in annual frequency: $\beta=0.89$ and $\gamma=4.89$; see Table 1a. In that case, the average for $\beta\left(\frac{C_{t+1}}{C_{t}}\right)^{-\gamma}\left(R_{2, t+1}-R_{1, t+1}\right)$ is 0.257 for annual data, which seems to be a high value. However, the estimated standard-deviation is also high (0.748), resulting in a t-statistic of 1.496. Thus, $E\left[\beta\left(\frac{C_{t+1}}{C_{t}}\right)^{-\gamma}\left(R_{2, t+1}-R_{1, t+1}\right)\right]$ is not significantly different from zero at the usual levels of $5 \%$ and $10 \%$. What seems to happen in that case, is that the variance of $\beta\left(\frac{C_{t+1}}{C_{t}}\right)^{-\gamma}\left(R_{2, t+1}-R_{1, t+1}\right)$ is too high, although the sample average is also high. Using Figure 1, it is clear that the high variance of $\beta\left(\frac{C_{t+1}}{C_{t}}\right)^{-\gamma}\left(R_{2, t+1}-R_{1, t+1}\right)$ is a result of the high variance of $\left(R_{2, t+1}-R_{1, t+1}\right)^{14}$. Therefore, there is no equity premium puzzle for Brazil due to the great variation observed for the equity premium.

It is worthwhile investigating the non-existence of the equity premium puzzle for Brazil from a different perspective. If we use annual data to compute the Brazilian equity premium, we obtain an average

\footnotetext{
${ }^{14}$ See also Bonomo and Domingues(2000) who argue that $\frac{C_{t+1}}{C_{t}}$ is also relatively volatile.
} 
of $29.06 \%$ per year for the $1975-1994$ period. Compared to the U.S. long-term value (1889-1978) of 6.18\% per year, the risk premium here is almost five times that of the U.S. Even taking into account that that the 20-year performance may not be maintained in the very long run, the Brazilian equity premium is impressive. However, equally impressive is its estimated $94.22 \%$ standard deviation. Hence, if we test the null hypothesis that $E\left(R_{2, t+1}-R_{1, t+1}\right)=0$, we arrive at a $t$-statistic of 1.379 , which does not reject the hypothesis that the Brazilian equity premium is zero at the usual significance levels. Seen from this perspective, there is no equity premium puzzle for Brazil because there is no equity premium either.

If the same type of test is carried out for the U.S. economy, using the returns from the Dow-Jones index and the interest rate from one-year U.S. Treasury Bills ${ }^{15}$, we get opposite results. The null hypothesis of $E\left(R_{2, t+1}-R_{1, t+1}\right)=0$ is rejected at the $5 \%$ level, with a $t$-statistic of 1.99. Hence, in the U.S., there is both equity premium and equity premium puzzle.

\section{Conclusions.}

The purpose of this article was to present estimates for the risk aversion coefficient, the discount rate of the future utility, and the inter-temporal elasticity of substitution in consumption for Brazil. We used three different utility function specifications in the CCAPM. In each case, starting from Euler Equations, we estimated these structural parameters using the generalized method of moments (GMM) and tested the model's over-identifying restrictions using Hansen's (1982) $T \times J$ test.

The results allow us to make some inference about each model's

${ }^{15}$ Both series were extracted from the DRJ (Citibase)'s database, from the 197 4:1 up to 1999:1 period, in monthly frequency. 
performance in the Brazilian case and about the Brazilian consumer's behavior when facing risk, inter-temporal substitution in consumption, and future utility discount. These can be summarized in the following way:

1. A reasonable estimate for the discount factor $\beta$ in Brazil is 0.90. When comparing Brazilian and U.S. consumers it is obvious that the Brazilian consumer is more impatient than its U.S. counterpart, who has a discount factor close to one.

2. We may conclude that the inter-temporal elasticity of substitution in consumption is not very high in Brazil, with values predominately close to 0.25 . This can be interpreted in two opposite ways: as more evidence of consumption smoothing, or, as evidence that the Brazilian consumer is liquidity constrained ${ }^{16}$.

3. We found ambiguous results for relative risk aversion: for the CRRA utility model, using annual data, we found relatively high risk aversion values (a median of 4.89). For all other models and time frequencies, we arrived at a relative risk aversion that was predominately within the $\left[\frac{1}{2}, 1\right]$ interval, with strong evidence of risk neutrality. In the international comparisons, we concluded that Brazilians are more risk averse than U.S. citizens. However, it is worth emphasizing that for the Kreps-Porteus utility model we found evidence to the contrary.

Although we cannot be conclusive regarding the inter-temporal elasticity of substitution in consumption, we should prefer low elasticity estimates, which was the predominant result for annual data. Notice that this result is consistent with the existence of an incipient credit market in Brazil. Regarding relative risk aversion, a high risk aversion result must be preferred for two reasons: (i) the results of

\footnotetext{
${ }^{16}$ This conclusion is in accordance with estimates done for Brazilian data in Reis et alli (1998), in which it was estimated that $80 \%$ of Brazilian consumers are of the restricted type, in the Campbell and Mankiw (1989) sense.
} 
low risk aversion were obtained for Kreps-Porteus utility, the only model that showed signs of not being consistent with the data in testing, and (ii) we have, for annual data, strong evidence of high relative risk aversion; see the discussion above on seasonal adjustment.

In Hansen's over-identifying restriction tests, the estimated models were rarely rejected, which lead us to conclude that, contrary to the U.S. case, there is no equity premium puzzle for Brazil. According to our preliminary investigation, the non-existence of the equity premium puzzle is due to the fact that the Brazilian equity premium is very volatile. As a consequence, we cannot reject that the hypothesis that the Brazilian equity premium is statically zero. Thus, we concluded that there is no equity premium puzzle for Brazil because there is no equity premium.

Finally, the three models estimated here could be evaluated in an alternative way. In the over-identifying restrictions tests, the only specification that was rejected by the data was the model with Kreps-Porteus utility. However, it is well known that the $T \times J$ test has low power (see Newey (1985)). We could find alternative ways of choosing models using a different specification test. Diebold, Ohanian and Berkowitz (1998), among others, propose an interesting way of evaluating models, that compares data and models in all frequencies, weighting the differences between them using different weights depending on the frequency. This "weighted distance" between data and models can be used to evaluate the latter.

Submitted in July 2000. Revised in July 2001.

\section{References}

Abel, A. 1990. "Asset Prices under Habit Formation and Catching Up with the Joneses". American Economic Review 80:Papers and Proceedings 38-42. 
Andrews, D. 1991. "Heteroskedasticity and Autocorrelation Consistent Covariance Matrix Estimation". Econometrica 59:817-858.

Bonomo, Marco A.C. \& Gabriela B. Domingues 2000. "Brazilian Assset Pricing Puzzles". Mimeo, EPGE-FGV.

Bernanke, B. 1985. "Adjustment Costs, Durable Goods and Aggregate Consumption". Journal of Monetary Economics .

Campbell, J. 1993. "Intertemporal Asset Pricing without Consumption Data". American Economic Review, 83:487-512.

Campbell, J., A. Lo \& A. Mackinley 1997. The Econometrics of Financial Markets. Princeton: Princeton University Press.

Campbell, J. \& G. Mankiw 1989. "Consumption, Income and Interest Rates: Reinterpreting the Time Series Evidence". NBER Macroeconomics Annual.

Constantinides, G. 1990. "Habit Formation: A Resolution of the Equity Premium Puzzle". Journal of Political Economy 98: 519543.

Diebold, F., Ohanian, L. \& J. Berkowitz 1989. "Dynamic Equilibrium Economies: a Framework for Comparing Models and Data". Review of Economic Studies, 65:433-451.

Deaton, A. 1992. Understanding Consumption. New York: Oxford University Press.

Duffie, D. 1992. "The Nature of Incomplete Security Markets" in

J. Laffont (org.). Advances in Economic Theory. Cambridge University Press.

Epstein, L. \& S. Zin 1989. "Substitution, Risk Aversion, and the Temporal Behavior of Consumption and Asset Returns: A Theoretical Framework". Econometrica 57:937-968.

Epstein, L. \& S. Zin 1991. "Substitution, Risk Aversion, and the Temporal Behavior of Consumption and Asset Returns: An Em- 
pirical Investigation". Journal of Political Economy 99:263-286. GREENE, W.H. 1997. Econometric Analysis. Prentice Hall.

Grossman, S. \& G. Laroque 1989. "Asset Pricing and Optimal Portfolio Choice in the Presence of Illiquid Durable Consumption Goods". Econometrica 58:25-52.

Hall, R. 1988. "Intertemporal Substitution in Consumption". Journal of Political Economy 96:221-273.

Hamilton, J. 1994. Time Series Analysis. Princeton: Princeton University Press.

Hansen, L. 1982. "Large Sample Properties of Generalized Method of Moments Estimators". Econometrica 50:1029-1054.

Hansen, L. \& K. Singleton 1982. "Generalized Instrumental Variables Estimation of Nonlinear Expectations Models". Econometrica 50(5): 1269-1286.

Hansen, L. \& K. Singleton 1983. "Stochastic Consumption, Risk Aversion and the Temporal Behavior of Asset Returns". Journal of Political Economy 91:249-266.

Hansen, L. \& K. Singleton 1984. Errata do artigo "Generalized Instrumental Variables Estimation of Nonlinear Expectations Models". Econometrica 52(1):267-268.

Hansen, L. \& R. Jagannathan 1991. "Restriction on Intertemporal Marginal Rates of Substitution Implied by Asset Returns". Journal of Political Economy 99:225-262.

Kreps, D. \& E. Porteus 1978. "Temporal Resolution of Uncertainty and Dynamic Choice Theory". Econometrica 46:185-200.

Lucas, R. 1978. "Asset Prices in an Exchange Economy". Econometrica 46:1429-1445.

Mankiw, G. 1986. "The Equity Premium and the Concentration of Aggregate Shocks". Journal of Financial Economics 17:211-219. 
Mátyás, L. 1999. Editor, Generalized Method of Moments Estimation. Cambridge: Cambridge University Press.

Mehra, R., \& E. Prescott 1985. "The Equity Premium: A Puzzle". Journal of Monetary Economics 15:145-161.

Newey, W. 1985. "Generalized Method of Moments Specification Testing". Journal of Econometrics 29:229-256.

Newey, W. \& K. West 1987. "A Simple, Positive Semi-Definite, Heteroscedasticity and Autocorrelation Consistent Covariance Matrix". Econometrica 55:703-708.

Reis, E. J., J.V. Issler, F. Blanco \& L. Carvalho 1998. "Renda Permanente e Poupança Precaucional: Evidências Empíricas para o Brasil no Passado Recente". Pesquisa de Planejamento Econômico, 28:233-272.

Romer, D. 1996. Advanced Macroeconomics. McGraw-Hill.

Runkle, D. 1991. "Liquidity Constraints and the Permanent Income Hypothesis: Evidence from Panel Data". Journal of Monetary Economics 27:73-98.

Scheinkman, J.A., \& L. Weiss 1986. "Borrowing Constraints and Aggregate Economic Activity". Econometrica: 54:23-45. 
. 